\title{
Culture of the Japanese Spiny Lobster Panulirus japonicus from Egg to Juvenile Stage
}

\author{
Jiro Kittaka* and Ko-ichi Kimura* \\ (Received October 27, 1988)
}

\begin{abstract}
About 20,000 first stage phyllosomas were cultured at $24-28^{\circ} \mathrm{C}$, being fed with nauplii of Artemia. Later stages were fed on Mytilus edulis ovary. Five phyllosomas reached stage VIII, approximately 200 days after hatching. Three phyllosomas reached stage XI and two individuals metamorphosed into pueruli 340-391 days (cf. 306 days for Jasus lalandii) after hatching. More than one molt was observed in several stages: 6 molts for stage VIII, 3 for IX and 3 for $X$. The intermolt interval was steady at 11-12 days throughout VIII$X$, and slight morphological changes were observed at each molt. Stage VIII may be separated into 2 parts: early, consisting of 3 instars without pleopod buds, and advanced, consisting of 3 instars with pleopod buds. Number of stages should be increased to 12 , and number of instars will be estimated at 29 . Under intensive illumination, repeated molting occurred without morphological change: 9 molts for stage VIII and 5 for $X$. The hepatopancreas of the newly metamorphosed puerulus gradually became visible, and the puerulus molted into the juvenile stage after 12-15 days. No feeding was observed during the puerulus stage, yet juveniles immediately fed on Mytilus edulis.
\end{abstract}

The Japanese spiny lobster Panulirus iaponicus occurs on the exposed rocky shores of Japan isles arc washed by the Kuroshiwo Current. Since the beginning of this century, the landings have been steady at 1,000-1,500 $\mathrm{t}$ annually. ${ }^{1)}$ This stability is considered to have been due to both less fluctuation in recruitment of pueruli after the long pelagic phyllosoma period ${ }^{13}$ and the long history of strict regulation of fishing gear, seasons and grounds. $^{2}$ Restocking and aquaculture are often used to increase population size and production in marine species. Nonaka et al., ${ }^{3)}$ Saisho $^{4-8)}$ and Inoue $^{7-103}$ tried culturing the phyllosomas of $\boldsymbol{P}$. japonicus, but no reliable culture method was established.

The stage of phyllosoma development in palinurids has usually been based on examination of samples collected in the ocean. Features used to distinguish mid- and late phyllosoma stages of other palinurids have been the appearance and cleavage of uropods and pleopods, segmentation of the abdomen, and appearance of gills. ${ }^{\theta-14)}$ Eleven stages were described for Panulirus interruptus, ${ }^{11)} P$. japonicus, ${ }^{9},{ }^{10)}$ Jasus lalandii, ${ }^{12)} \mathrm{J}$. edwardsii ${ }^{13)}$ and 9 stages for $P$. cygnus. ${ }^{14,153}$ It is thought that in some stages there is more than one instar, but morphological change between instars has seldom been examined. This has made staging phyllosoma confusing particularlly after the mid-stage. It is hypothesized that phyllosomas are subject to the subsurface transport towards coast after the mid-stage. ${ }^{19}$ Culture of phyllosoma to settlement would fill the gap in our knowledge of the early life history of spiny lobsters.

The authors cultured the phyllosomas of the cold temperate species Jasus lalandii, ${ }^{17)}$ a Jasus hybrid ${ }^{18)}$ and Palinurus elephas ${ }^{19)}$ to the puerulus stage. The seguence of instars and stages has been given for these cold temperate species. The authors have applied the similar culture method to P. japonicus.

\section{Materials and Methods}

\section{Materials}

Mature $P$. japonicus (range of carapace length: 62-78 mm for females and $52-98 \mathrm{~mm}$ for males) were caught at Chikura along the south-eastern coast of Boso Peninsula in 1984 and 1985 and kept in a FRP tank (dimensions: $2.5 \mathrm{~m} \times 1.2 \mathrm{~m} \times$ height $0.7 \mathrm{~m}$ ) with slow running seawater and aeration. There were 20 females and 5 males at the beginning of 1986 and 17 females and 5 males at the end of 1987 . Water temperature ranged

* School of Fisheries Sciences, Kitasato University, Sanriku, Iwate 022-01, Japan（霫高二郎，木村康一： 北里大学水痤学部). 
between $12^{\circ} \mathrm{C}$ in winter and $22^{\circ} \mathrm{C}$ in summer. Mytilus edulis were given as food daily. Eggbearing females were found each summer. Hatched phyllosomas were used for the culture experiments in 1987.

\section{Methods}

Approximately 20,000 phyllosomas were introduced into a $100 /$ circular culture tank on the day of hatching. Sea water treated with a $5 \mu \mathrm{m}$ ceramic filter and ultra-violet sterilizer was supplied at the bottom of the culture tank in the recirculating system. Cultured marine Chlorella was added at several million cells per $\mathrm{m} l$ to the tank. Water temperature was maintained at approximately $25-26^{\circ} \mathrm{C}$. The larvae were fed with Artemia nauplii at the initial stages and small pieces of Mytilus edulis ovary at the more advanced stages. Water temperatures, salinity, $\mathrm{pH}$, density of Chlorella, rate of water exchange and amount of food given were measured daily. Staging was done based on the description by Inoue, ${ }^{\theta, 103}$

After 124 days survived phyllosomas were transferred into two $16 /$ circular glass tanks. One tank was exposed at 140 lux illumination during night and another at 560 lux.

After metamorphosis, the pueruli were initially kept in the same tank so that settlement behaviour could be observed. Later, older puerulus was transferred into a plastic cage (dimensions: $13 \mathrm{~cm}$ $\times 9 \mathrm{~cm} \times$ height $11 \mathrm{~cm}$ ) placed in another tank. Changes in external appearance and behaviour were observed throughout the puerulus stage.

\section{Results}

\section{Reproduction}

The annual cycle of reproduction for $P$. japonicus in the laboratory tanks is shown in Fig. 1.

Molting occurred from August to December with a peak in September for males and almost all year round with a peak from September to February for females. Mating probably occurred in June and July as about $70-80 \%$ females were found bearing eggs in those months. In July 1987, 5 egg-bearing females were placed in a FRP tank. About 400,000 phyllosomas hatched out in the middle of August. The pattern of reproduction was similiar to that of this species in the wild. ${ }^{16)}$

\section{Larval Growth and Survival}

The results of the communal rearing of the phyllosomas are shown in Table 1.

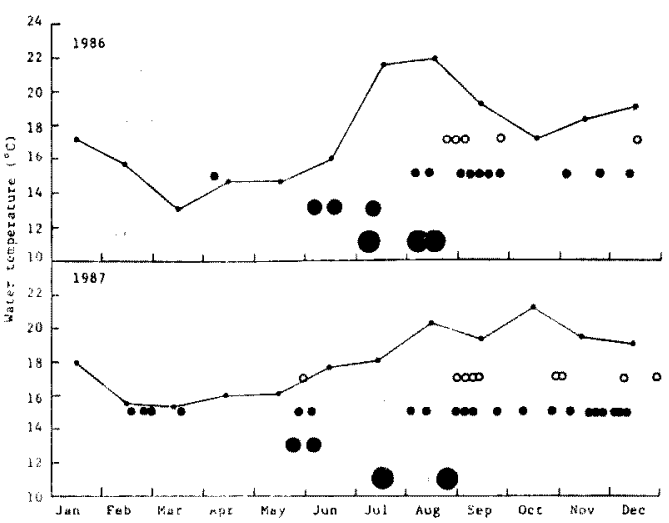

Fig. 1. Reproductive cycle of adult Panulirus japonicus in the laboratory at Sanriku in 1986 and 1987.

Monthly average water temperature is shown with spots on a curve $(\cdot)$. Molting for males, molting for females, egg-bearing, and hatching are shown with open circles $(0)$, small-sized closed circles $(\bullet)$, medium-sized closed circles $(\bullet)$, and large-sized closed circles $(\bullet)$, respectively.

Number of males and females was 5 and 20 in 1986 and 5 and 17 at the end of 1987.

The intermolt period was steady at about 6 and 7 days for the first and second stage phyllosomas, respectively. The intermolt period was prolonged to about 18 days at the third stage because two molts ( 2 instars with different elongation of the fourth pereiopods) were found in this stage. Three instars were frequently found at the fourth stage, as indicated by the elongation and bifurcation of the fourth pereiopods. The precise number of instars could not be determined for the mid- stages because phyllosomas were not reared individually.

Survival was very low up to mid-stage $(8 / 20,000$ $=0.04 \%$ for 139 days), but was higher $(4 / 8=50 \%$ for 252 days) at advanced stages. Two phyllosomas metamorphosed into pueruli 340 and 391 days after hatching; other 2 phyllosomas reached the tenth and eleventh stages.

\section{Molting of the Mid- and Late Stage Phyllosoma}

Molting was monitored individually for 5 survivors from the eighth stage. Molting freguency and stage of development are shown individually in Table 2.

The sequence of development of $P$. japonicus was similar to other palinurids. ${ }^{9-14}$ It will be found that most phyllosomas have 6 instars at the 
Table 1. Rearing of phyllosomas of $P$. japonicus

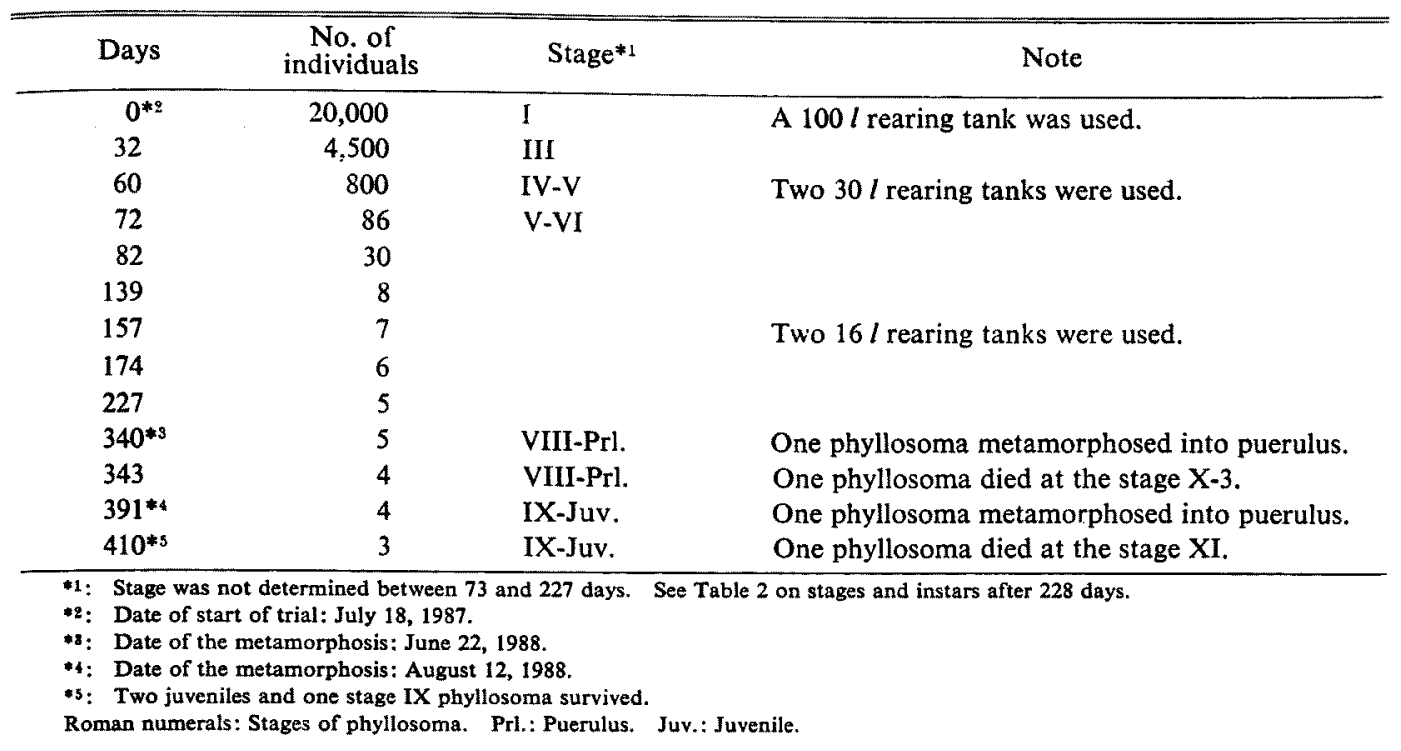

Table 2. Rearing of mid-and late stage phyllosomas of $P$. japonicus

\begin{tabular}{|c|c|c|c|c|c|c|c|c|c|c|}
\hline \multirow{2}{*}{$\begin{array}{l}\text { Stage } \\
\text { Instar }\end{array}$} & \multicolumn{2}{|c|}{1} & \multicolumn{2}{|c|}{$2^{* 2}$} & \multicolumn{4}{|c|}{ Individual phyllosoma No. } & \multicolumn{2}{|c|}{$5^{* 5}$} \\
\hline & Day & $\begin{array}{l}\text { Inter- } \\
\text { molt } \\
\text { days }\end{array}$ & Day & $\begin{array}{c}\text { Inter- } \\
\text { molt } \\
\text { days }\end{array}$ & Day & $\begin{array}{c}\text { Inter- } \\
\text { molt } \\
\text { days }\end{array}$ & Day & $\begin{array}{l}\text { Inter- } \\
\text { molt } \\
\text { days }\end{array}$ & Day & $\begin{array}{l}\text { Inter- } \\
\text { molt } \\
\text { days }\end{array}$ \\
\hline \multicolumn{11}{|c|}{ VIII-1*1 } \\
\hline-2 & & & & & 243 & 10 & & & 237 & 10 \\
\hline-3 & & & & & 253 & 12 & 237 & 12 & 247 & 15 \\
\hline-4 & & & 248 & 01 & 265 & 12 & 249 & 12 & 262 & 17 \\
\hline-5 & & & 259 & 11 & 277 & 12 & 261 & 12 & $279^{* 3}$ & 18 \\
\hline-6 & 246 & 11 & 270 & 11 & 289 & 11 & 273 & 13 & $297^{* 3}$ & 17 \\
\hline-7 & & & & & & & & . & 314 & 16 \\
\hline-8 & & & & & & & & & 330 & 20 \\
\hline-9 & & & & & & & & & 350 & 16 \\
\hline IX-1 & 257 & 13 & 281 & 10 & 300 & 11 & 286 & 14 & 366 & 20 \\
\hline-2 & 270 & 14 & 291 & 11 & 311 & 11 & 300 & 15 & 386 & 20 \\
\hline-3 & 284 & 12 & 302 & 12 & 322 & 11 & 315 & 15 & 406 & 15 \\
\hline-4 & & & & & 333 & $12^{* 3}$ & & & $421^{* 3}$ & \\
\hline$X-1$ & 296 & 11 & 314 & 11 & 345 & 11 & 330 & 14 & & \\
\hline-2 & 307 & 11 & 325 & 12 & 356 & 11 & 344 & 15 & & \\
\hline-3 & 318 & 10 & 337 & & 367 & 12 & 359 & 15 & & \\
\hline-4 & & & & & & & 374 & $15^{* 3}$ & & \\
\hline-5 & & & & & & & 388 & $04 * 3$ & & \\
\hline $\mathrm{XI}-1$ & 328 & 12 & & & 379 & 12 & 404 & & & \\
\hline Prl. & 340 & 15 & & & 391 & 12 & & & & \\
\hline Juv. & 355 & & & & 403 & & & & & \\
\hline \multicolumn{11}{|c|}{$\begin{array}{l}\text { *1 Stages were monitored individually } 228 \text { days after hatching. The first instar of the eighth stage was found by molt shells of phyl- } \\
\text { losomas No. } 3 \text { and } 5,243 \text { and } 237 \text { days after hatching. respectively. } \\
\text { *2 Died } 343 \text { days after hatching. } \\
\text { *8 Molted repeatedly without morphological change. } \\
\text { *4 Died } 410 \text { days after hatching. } \\
\text { *5 Died } 423 \text { days after hatching. Phyllosomas No. } 4 \text { and } 5 \text { were cultured under intensive illumination. }\end{array}$} \\
\hline
\end{tabular}


Table 3. Distinguishing features of the mid- and late stage phyllosoma larvae of $P$. japonicus

\begin{tabular}{|c|c|c|c|c|c|}
\hline Stage & Instar & $\begin{array}{l}\text { Fith } \\
\text { pereiopod }\end{array}$ & Pleopods & Uropods & Abdomen \\
\hline \multirow[t]{6}{*}{ VIII } & 1 & Low bud & Absent & Low buds & non-segmented \\
\hline & 2 & " & " & $"$ & $"$ \\
\hline & 3 & $"$ & " & Buds & $"$ \\
\hline & 4 & Bud & Low buds & Bifid & $" \prime$ \\
\hline & 5 & " & $"$ & " & $"$ \\
\hline & 6 & $" 1$ & $"$ & $"$ & $"$ \\
\hline \multirow[t]{3}{*}{ IX } & 1 & Elongated & Bifid & $" \prime$ & $" \prime$ \\
\hline & 2 & " & $" \prime$ & $" \prime$ & " \\
\hline & 3 & Segmented & $"$ & $"$ & Segmented \\
\hline \multirow[t]{3}{*}{$\mathrm{X}$} & 1 & $"$ & " & " & $"$ \\
\hline & 2 & $" \prime$ & With appendix interna & $"$ & $" \prime$ \\
\hline & 3 & " & With lateral spine & $"$ & \\
\hline $\mathrm{XI}$ & & & & & Gill buds apparent \\
\hline
\end{tabular}

eighth stage, 3 at the ninth stage and 3 at the tenth stage. Molt intervals averaged 12.9 days (range: 10-21 days).

Molt intervals varied for individual phyllosomas depending on the culture conditions. The intermolt period was 11.1-11.8 days for the phyllosomas with less illumination (140 lux for phyllosoma No. 1, 2 and 3) and 13.8-16.7 days for those with intense illumination (560 lux for phyllosoma No. 4 and 5).

\section{Instars of the Mid-and Late Stage Phyllosoma}

Morphological changes were observed in the sequence of instars in each stage as shown in Table 3.

The fifth pereiopod was indicated as a bud in VIII-1 (instar 1 of the eighth stage), was segmented in VIII-4, elongated in IX-1, formed 5 segments in IX-3, and was complete in X-1. Pleopods appeared in VII-4, and showed signs of longitudinal cleft in IX-1. This process was complete in X-2 with appearance of the appendix interna. Uropods were indicated as swellings in VIII-1, cleavage began in VIII-4, and was complete in X-3.

The eighth stage may be separated into 2 parts: VIII-1, 2 and 3 and VIII-4, 5 and 6 , based on the distinct morphological difference in pleopods and cleavage of uropods. Gill buds, which have not been described on $P$. japonicus before, became elongate on maxillipeds and pereiopods in the eleventh (final) stage, several days before metamorphosis into the puerulus, although they were difficult to see early in the eleventh stage.

In most cases, the phyllosomas developed morphology with each molt. However, sometimes

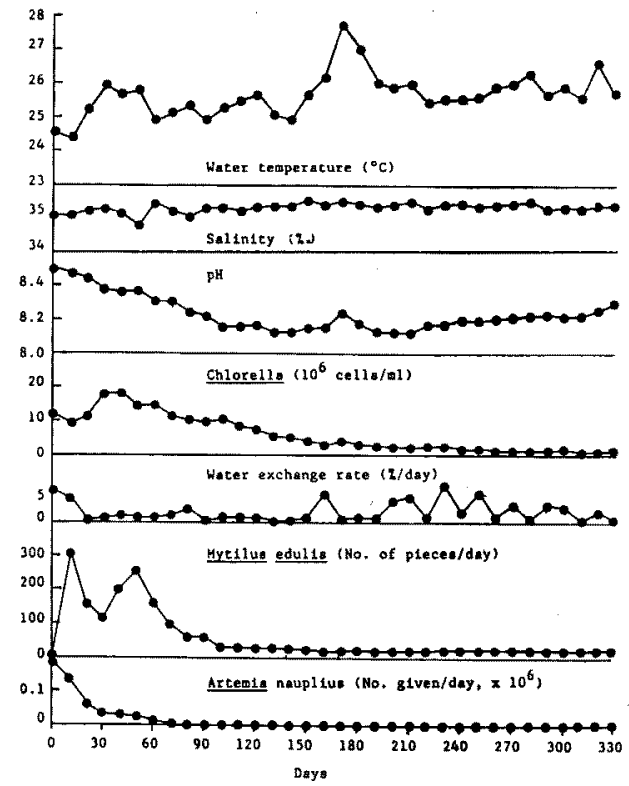

Fig. 2. Environmental and feeding condition in the rearing tank for the phyllosoma of Panulirus japonicus during the period from July 18, 1987 to June 22, 1988. Feeding amount indicates total amount of feed given daily per tank.

they repeated instars without significant morphological change, as seen in the eighth stage with 9 instars (phyllosoma No. 5), in the ninth stage with 4 instars (phyllosoma No. 3 and 5), and in the tenth stage with 5 instars (phyllosoma No. 4).

\section{Rearing Conditions}

Water temperature, water quality and feeding amount for the rearing tank are shown in Fig. 2. 
Table 4. Changes in appearance at metamorphosis of phyllosoma of $P$. japonicus

\begin{tabular}{|c|c|c|}
\hline \multicolumn{2}{|c|}{ Time before metamorphosis } & \multirow[b]{2}{*}{ Stage and changes of appearance } \\
\hline Day & Hour & \\
\hline 12 & & Molted into XI stage. \\
\hline 7 & & Abdomen increased thickness. \\
\hline 3 & & Gills became elongate. Thickness of abdoment is pronounced. \\
\hline 2 & & Stopped feeding. Sign of hepatopancreas retraction. \\
\hline 0 & 2 & Body colour became smoked-transparent. \\
\hline 0 & 1.5 & Eyestalks were bent backwards. \\
\hline 0 & 0.5 & Cephalothorax retraction. \\
\hline 0 & 0 & Metamorphosed into puerulus. \\
\hline
\end{tabular}

Previous work ${ }^{4-10)}$ with this species showed the optimum water temperature for culture at 24 $29^{\circ} \mathrm{C}$. In this experiment, water temperature was generally maintained at $24-26^{\circ} \mathrm{C}$ with the maximum at $28^{\circ} \mathrm{C}$. Salinity ranged between 34 and $35 \%$. Density of Chlorella was maintained at $10 \times 10^{6}-20 \times 10^{6} \mathrm{cells} / \mathrm{ml}$ in early period. It was later lowered to $3 \times 10^{8}-1 \times 10^{8}$ cells $/ \mathrm{m} l$ in proportion to the number of phyllosomas. Values of $\mathrm{pH}$ ranged from 8.5 at the baeginning to 8.0 at the end depending on density of Chlorella. Water of the rearing tank was exchanged approximately once every two weeks.

Phyllosomas were fed with Artemia nauplii at the initial period and Mytilus edulis ovary after the mid-period. Daily feeding amount was higher for the early culturing period because of the high density of phyllosomas. This may be a factor of heavy mortality during the early stage.

\section{Metamorphosis to Puerulus Stage}

Three phyllosomas (No. 1, 3 and 4) molted into the final stage of phyllosoma (Table 2, Fig. 3. A) 328,379 and 396 days after hatching, respectively. The period of the final stage was 12 days for each of the 2 animals to molt to puerulus. The change in the external appearance before metamorphosis is summarized in Table 4.

Increase in abdominal thickness and elongation of gill buds were observed at the beginning of the final stage of phyllosoma. Retraction of hepatopancreas and cessation of feeding are signs of the approaching molt. These changes at the final phyllosoma stage were basically similar to those of genus Jasus, but slight differences were observed in the indicators of imminent metamorphosis.

For $P$. iaponicus, on the day of the metamorphosis, the body colour of the phyllosomas became smoked-transparent and the individuals occasionally streched their eyes with the first pereiopods. Drastic changes occurred about one and one half hour before molting. Eyestalks were bent backwards along the dorsal side of the carapace, pereiopods became flaccid, and retraction of cephalothorax and abdomen became more pronounced. The new puerulus took $2-3 \mathrm{~min}$ to emerge dorsally through the thoracoabdominal membrane. The body of the newly molted puerulus was transparent (Fig. 3. B). It was carried by the current and at the same time swam rotating with occasional beating of pleopods. The swimming posture was in-between that of Jasus lalandii and Palinurus elephas: the second antennae were extended forwards and the pereiopods were slightly out-streched. Three or four days after metmaorphosis, the light-coloured hepatopancreas became visible (Fig. 3. C). Seven days after metamorphosis, one puerulus was transferred into a cage floating in the tank. The puerulus occupied a shelter in the cage in a tucking posture. About 12 days after metamorphosing, the hepatopancreas was very pronounced and bands of dark pigmentation developed on the second antennae (Fig. 3. D). The puerulus clung to the wall or bottom of the cage. It was very healthy but no feeding behaviour was observed. The puerulus molted into the first juvenile about 15 days after metamorphosis (Fig. 3. E).

The body colour of the first molt post-puerulus was pale-brown with ligh-coloured parts on the dorsal side of abdomen. The juvenile began to feed on the day of molting, and molted with 1218 intermolt days (Fig. 3. F).

\section{Discussion}

Staging of phyllosomas is generally arbitra$\mathrm{ry},{ }^{1-14)}$ but culturing individuals in the laboratory can better reveal the sequence of the instars or stages compared with examination of specimens from plankton samples. ${ }^{15,18)}$

Molt frequency varied depending on the stage 


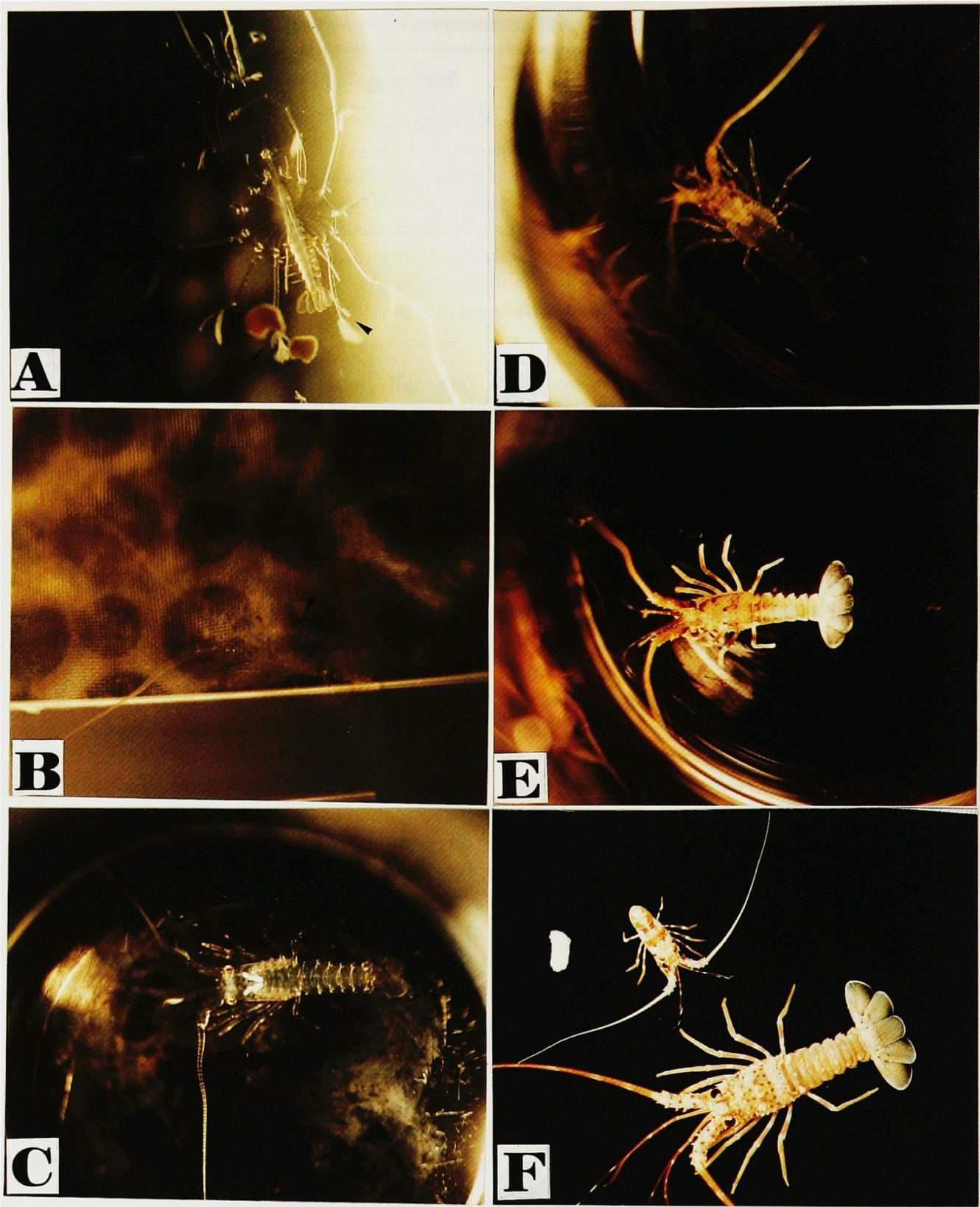

Fig. 3. Late stage larva and early juvenile of Panulirus japonicus.

A. The eleventh stage phyllosoma (body length: $32 \mathrm{~mm}$ ). The individual lost the endopods of the third and fourth pereiopod as indicated by arrows.

B. Newly molted puerulus (body length: $21 \mathrm{~mm}$, one day after metamorphosis) clinging on the screen net as indicated by an arrow.

C. Early stage of puerulus (6 days after metamorphosis). The V-shaped hepatopancreas became visible.

D. Late stage of puerulus (11 days after metamorphosis).

E. Newly molted post-puerulus (body length: $23 \mathrm{~mm}, 12$ days after metamorphosis).

F. Juveniles. Upper: the second stage juvenile, 18 days old (body length: $26 \mathrm{~mm}$ ). Lower: the sixth stage juvenile, 67 days old (body length: $48 \mathrm{~mm}$ ). 
of development of $P$. japonicus, as reported for Jasus. Gradual morphological change was usually observed at each molt, suggesting that "instar" can be used to indicate the growth stage of phyllosomas. However, molting without morphological change was occassionally observed. Because of the delicate structure of molt shells, observation was sometimes difficult. Detailed examination of living phyllosomas will be necessary to determine morphological change of instars precisely.

The average intermolt intervals was 11.4 days for the 3 individuals (phyllosoma No. 1, 2 and 3). The duration of the eighth stage was extraordinary long compared with other stages. The eighth stage may be separated into 2 parts: 3 early instars without pleopods buds and 3 advanced instars with pleopods buds. The length of the entire phyllosoma stage was 340 days (cf. 306 days for $J$. lalandi $i^{17,18)}$ ) for the fastest growing individual. It is probable that the phyllosoma development period of $P$. japonicus is of shorter duration in the ocean.

Assuming that there are 3 instars each at the mid-stages (the fifth, sixth and seventh stage), the number of instars of the entire phyllosoma stage of $\boldsymbol{P}$. japonicus is estimated at 29 ( 1 instar at stage I, 1 at II, 2 at III, 3 at IV, 3 at V, 3 at IV, 3 at VII, 6 at VIII, 3 at IX, 3 at $X$ and 1 at XI; cf. 15 instars for Jasus ${ }^{17},{ }^{8)}$ ).

Phyllosomas of $\boldsymbol{P}$. japonicus molted more frequently with shorter intermolt duration compared with $J$. lalandii. ${ }^{17,18)}$ In the laboratory, the phyllosomas of $\boldsymbol{P}$. japonicus often lost the elongate endopodite from the second, third and fourth pereiopods soon after the molting, which was not observed for $J$. lalandii. Pereiopods are very important in the capture of food animals and particles.

In our culture experiments, phyllosomas of Jasus lalandii, ${ }^{15)}$ a Jasus hybrid, ${ }^{17)}$ Palinurus elephas $^{18)}$ and $P$. japonicus metamorphosed into pueruli. This suggests that the culture conditions are adequate to support the life of phyllosoma. The complete development of 3 genera of palinurid was achieved by feeding mussels in the later stages..$^{17-19)}$ These culture experiments showed a very low survival rate during the early stage but much higher survival after mid-stage. High mortality at the early stage is considered to be due to water quality deterioration, particularly accumu- lation of organic materials derived from food. Determination of the optimum density of larvae and feeding amount in the culture tank is a key factor to improve survival at the initial stage.

Although late phyllosomas fed actively on, no feeding was observed during the puerulus stage in the presence of right type of food. ${ }^{17-18)}$ Presumably without feeding, the puerulus molted to the first juvenile stage, then it again began to feed on. The heaptopancreas occupies almost the entire cephalic part and is a major digestive organ of the phyllosoma. It was not visible at the early puerulus stage, appeared as the white coloured organ about 3 or 4 days after metamorphosis and developed to the V-shaped organ about a week before molting to the first juvenile stage. Nishida et al.* observed the atrophy of the digestive organ in puerulus of $J$. edwardsii. These observatisons strongly suggest no feeding during the puerulus stage.

Kinoshita $^{21)}$ collected pueruli of $P$. japnoicus and cultured them to the first juvenile stage in running seawater, with food consisting fish and shellfish. However, in our laboratory, the cultured pueruli of J. Ialandii and Jasus hybrid died before molting, even though food was provided. Previous success is therefore considered to have been due to sufficient water exchange and not due to feeding. The pueruli swam with pleopods beating in the water, or sank to the bottom of the tank. Under laboratory conditions, sinking to the bottom is considered to be avoided not only for phyllosoma but for early stage puerulus. In the present experiment, the puerulus of $P$. japonicus was kept in the phyllosoma culture tank until it showed clinging behaviour. Only then was it transferred into a cage suspended in the water. Thus, problems for puerulus culture have almost been resolved.

\section{Acknowledgements}

The authors wish to express their sincere thanks to the late Mr. Tatsuo Wada, Chiba Prefectural Awa Fisheries High School for arranging shipment of experimental spiny lobsters. The authors are indebted to the following former students of the School of Fisheries Sciences, Kitasato University, during the course of this study: Mr. Masa-aki Iwai, Mr. Masanori Yoshimura, Mr. Tada-aki Nemoto and Mr. Tadahiko Saito.

* Oral presentation at the Annual Meeting of the Oceanographycal Society of Japan held at Nagasaki on 14 October 1988. 
The authors thank Dr. J. D. Booth, Fisheries Research Center, New Zealand for his review of the manuscript. This work wassupported in part by a Grant-in-Aid from the Ministry of Education, Culture and Science, Japan.

\section{References}

1) M. Nonaka: Bull. Shizuoka Pref. Fish. Exp. St., 16, 31-42 (1982).

2) K. Kawaguchi: in "Fish Ranching" (ed. Fishery Agency), Shigenkyokai, Tokyo, 1983, pp. 90-109.

3) T. Nonaka, Y. Oshima, and R. Hirano: Suisanzoshoku, 5, 13-15 (1958).

4) T. Saisho: Mem. Fac. Fish. Kagoshima Univ., 11, 18-23 (1962).

5) T. Saisho: Inf. Bull. Planktol. Japan., 13, 69-71 (1966).

6) T. Saisho: Mem. Fac. Fish. Kagoshima Univ., 15, 177-239 (1966).

7) M. Inoue and M. Nonaka: Nippon Suisan Gakkaishi, 29, 211-218 (1963).

8) M. Inoue: Nippon Suisan Gakkaishi, 31, $902-$ 906 (1965).
9) M. Inoue: Nippon Suisan Gakkaishi, 44, 457475 (1978).

10) M. Inoue: Special Rep. Kanagawa Pref. Fish. Exp. St., 1, 1-91 (1981).

11) M. W. Johnson: Proc. Calif. Acad. Sci., 29, 129 (1956).

12) B. I. Silberbauer: Investl. Rep. Div. Sea. Fish. S. $A f r ., 92,1-70$ (1971).

13) J. H. R. Lesser: N. Z. J. Mar. Frashwater Res., 12, 357-370 (1978).

14) R. G. Chittleborough and L. R. Thomas: Aust. J. Mar. Freshwater Res., 20, 199-223 (1969).

15) S. J. Braine, D. W. Rimmer, and B. F. Phillips: CSIRO Div. Fish. Oceanogr. Rep., 102, 1-23 (1979).

16) B. F. Phillips and P.S. McWilliam: Can. J. Fish. Aquat. Sci., 43, 2153-2163 (1986).

17) J. Kittaka: Nippon Suisan Gakkaishi, 54, 87-93, (1988).

18) J. Kittaka: Nippon Suisan Gakkaishi, 54, 413417 (1988).

19) J. Kittaka: Nippon Suisan Gakkaishi, 54, 11491154 (1988).

20) Y. Oshima: Suisan Gakkaiho, 8, 231-238 (1946).

21) T. Kinoshita: Zool. Mag., 46, 391-399 (1934). 